
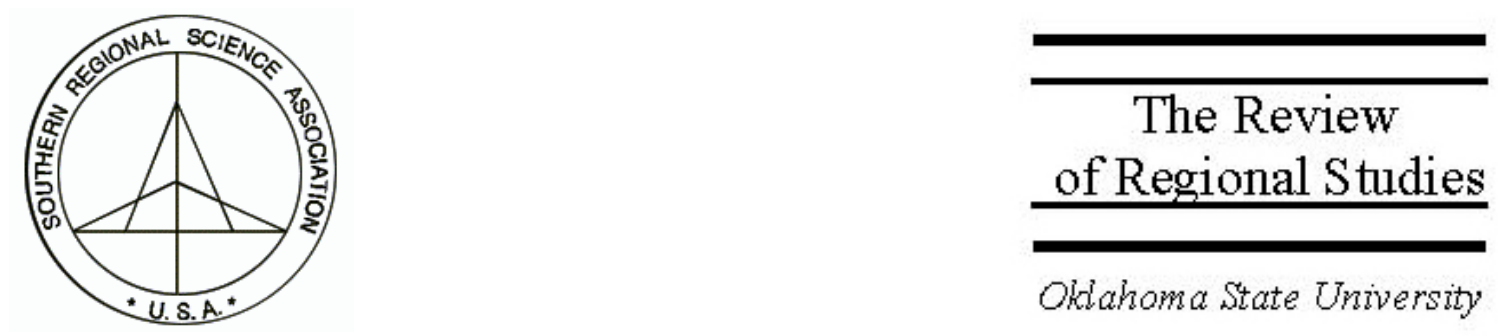

\title{
Regional Innovative Capacity with Endogenous Employment: Empirical Evidence from the U.S.
}

\author{
Mary Riddel \\ Center for Business and Economic Research, University of Nevada at Las Vegas \\ 4505 Maryland Parkway, Las Vegas, NV, 89154-6002, email: riddel@ccmail.nevada.edu \\ R. Keith Schwer \\ Center for Business and Economic Research, University of Nevada at Las Vegas \\ 4505 Maryland Parkway, Las Vegas, NV, 89154-6002, email: schwer@unlv.edu
}

\begin{abstract}
Using the endogenous growth model proposed by Romer (1990) and operationalized by Stern, Porter, and Furman (2000), we seek to identify factors that affect innovative capacity in the U.S. We find strong evidence of endogeneity between employment growth and innovative capacity. In response, we estimate a generalized two-stage random effects model of hi-tech employment and patenting activity. We find that the stock of knowledge (standing on shoulders effect), industry R\&D expenditures, and the number of high-tech employees explain the rate of change of innovation among the states during the 1990s. The stock of human capital also influences the innovation rate. Our findings suggest that patenting activity and wages in the high-tech sector are the primary forces influencing the demand for high-tech labor.
\end{abstract}




\section{STATE-LEVEL INNOVATIVE CAPACITY}

A region's innovative capacity is defined as its potential to produce a stream of commercially relevant innovations (Stern, Porter, and Furman 2000). Studies have found that the development of innovative capacity rests upon three key issues: the stock of research and development (R\&D) funds, the available labor pool, and the quality of educational institutions reflected in human capital (Feldman and Florida 1994; Anselin, Varga, and Acs 1997; Jaffe 1989). Of primary importance is the stock of R\&D funds, whether industry-based or university-based, that can support new technologies, designs, ideas, and innovative production methods, thereby affecting the marginal product of R\&D for innovative capacity (Kortum 1997; Stern, Porter, and Furman 2000).

Past research examining innovative capacity at the state or metropolitan statistical area (MSA) level has typically focused on the marginal product of industrial and university R\&D expenditures treating high-tech employment as an exogenous force (Feldman and Florida 1994; Anselin, Varga, and Acs 1997; Jaffe 1989). High-tech employment, however, may be endogenous, resulting in inconsistent model coefficients when endogeneity is ignored. Thus, it seems reasonable to examine the assumption of endogeneity and correct for possible bias if simultaneity can be established.

Using the endogenous growth model proposed by Romer (1990) and operationalized by Stern, Porter, and Furman (2000), we seek to identify factors that affect innovative capacity in the U.S. We modify Stern, Porter, and Furman's (2000) model for endogenous growth in innovative capacity internationally to accommodate the small open economies of the U.S. states. Using the Durbin-Wu-Hausman (DWH) test, we find strong evidence of simultaneity. In response, we estimate a generalized two-stage random-effects model to account for endogeneity between technological innovation and high-tech employment.

\section{LITERATURE REVIEW}

Using data from the 1970s and early 1980s, Jaffe (1989) found that university R\&D spending had a positive and significant effect on corporate patents, particularly in certain high-tech sectors. In a cross-sectional data set from 1982, Anselin, Varga, and Arcs (1997) also found significant spillover effects between university research, innovative activity, and corporate R\&D investment. Specifically, universities provide a pool of skilled labor that meets advanced, hightech, human-capital requirements. As important, however, are the spin-offs from university research, both basic and applied, that form viable commercial enterprises. Thus, the location of high-tech centers near major research universities is no accident.

A host of papers have looked at the geographic and spatial components of innovative development (Feldman and Florida 1994; Anselin, Varga, and Arcs 1997; Stohr 1986; Sivitanidou and Sivitanides 1995; Malecki 1981; Wilkerson 2002). These studies looked at spatial interactions, including spillover effects and geographic patterns of university, federal, and private R\&D spending. For the most part, these studies find evidence of spillover effects from university research externalities into regional technological innovation and the high-tech labor market. A few studies, however, have found that the relationship is either weak or nonexistent 
(Markusen, Hall, and Glasmeier 1986; Howells 1984). On another note, Wilkerson (2002) shows that city size is an important determinant of the size of the high-tech work force.

The bulk of the work to date has been interested primarily in spillovers from R\&D and their effects on the labor market and growth in innovations. The causal links between employment growth and innovative capacity have been largely ignored, however. Papers such as Felman and Florida (1994) and Anselin, Varga, and Arcs (1997), based on cross-sectional data with spatial modeling to capture spillover effects, do not investigate the economic impacts of changes in innovative capacity on employment growth. Jaffe (1989), using a time series, also examines R\&D spillover effects from the 1970s and early 1980s assuming exogenous employment growth. It seems likely that employment growth, particularly high-tech employment growth, may be endogenous to the model.

Another component of innovative capacity that has been largely ignored at the regional level is the concept of the stocks and flows of ideas. Endogenous growth models like those proposed by Romer (1990) shed light on the relationship between new knowledge generation, economic growth, and the existing pool of innovative capacity. Termed the "standing on shoulders" effect by Stern, Porter, and Furman (2000), the stock of ideas can affect the rate of new-idea generation. Ignoring the influence of the stock of ideas, or innovative capacity, can potentially bias estimates of the effect of R\&D spending or employment growth on new-idea development. Thus, a model that explicitly includes the stock of ideas, in terms of the stock of patents, may prove useful.

In the following section, we develop a model that relates employment growth, innovative capacity, and R\&D spending at the state level. Past research has investigated these relationships for endogenous growth in different countries' economies (Stern, Porter, and Furman, 2000). The same model may be applied to analyze regional growth among the states in the U.S. Based on the endogenous growth literature proposed by Romer (1990), the model used here expands that proposed by Jaffe (1989). We explicitly include employment to elucidate the complexities of innovative capacity and employment growth. The model is particularly useful because it allows for the stock of innovations to promote new innovation.

\section{A MODEL FOR INNOVATIVE CAPACITY WITH ENDOGENOUS EMPLOYMENT}

The national endogenous growth model proposed by Romer (1990) and applied by Stern, Porter, and Furman (2000) states that:

$$
\dot{A}_{t}=\delta H_{A, t}^{\lambda} A_{t}^{\phi} .
$$

Equation (1) is a Cobb-Douglas ideas production function. According to this relationship, the growth rate of new ideas (or innovation) is a function of the current stock of ideas (or innovation capacity), $A_{t}$, and $H_{t}$, the resources employed in creating new ideas. Technological change is endogenous in this model because the rate of idea development responds to the current stock of ideas. The environment for growth in innovative capacity is likely to vary across states independent of the local stock of ideas workers (Rowen 2000). Local laws, regulations, economic conditions, institutions, and public policy may affect the rate of new-ideas production. 
Another key component of state-level innovative capacity is the composition of R\&D funding. Stern, Porter, and Furman (2000) claim that public R\&D spending typically supports the current $R \& D$ infrastructure, whereas private $R \& D$ expenditures reveal the underlying environment for expanding innovative capacity. As such, a large share of total R\&D expenditures derived from private sources reflects a competitive innovation environment. In addition, the decentralization of public funding of higher education among the 50 states and the presence of many private universities has created a competitive environment for research funding from public sources (Mowery and Rosenberg 1993).

Following Stern, Porter, and Furman (2000), we combine Romer's endogenous technical growth model with Nelson's literature concerning national innovative capacity (Nelson 1993) and Porter's concept of industrial competitive advantage (Porter 1990) to produce a state-level production function for new ideas as:

$$
\dot{A}_{j, t}=\delta_{j, t} X_{j, t}^{\theta} H_{A j, t}^{\lambda} A_{j, t}^{\phi} .
$$

As before, $\dot{A}_{j, t}$ is the growth rate of new technologies in state $j$ during year $t, H_{A j, t}$ is the stock of capital and labor devoted to ideas production, and $A_{j, t}$ is the stock of ideas available to researchers. Additionally, $X_{j, t}$ refers to state-level variables that can influence innovative capacity such as economic geography, expenditures on education, and fiscal support such as tax breaks for R\&D expenditures. As it stands, equation (2) is a Cobb-Douglas production function for ideas generation, an expansion of (1). We can derive a linear estimable form of the model by adding a multiplicative stochastic component and then taking logs. Thus, the estimable form of the equation is:

$$
\ln \dot{A}_{j, t}=\beta+\theta \ln X_{j, t}+\lambda \ln H_{A j, t}+\phi \ln A_{j, t}+\varepsilon_{j, t}+v_{j} .
$$

In our empirical model, state-level patenting is used as a summary statistic for growth in innovative capacity. Specifically, $A_{j, t}$ is the number of new patents issued annually to inventors from each state by the U.S. Patent Office. Idiosyncratic state-specific factors are represented collectively by $X_{j, t}$. There are two sources of model error. The variable $v_{j}$ represents errors in the state-level intercept. In contrast, $\varepsilon_{t, j}$ is a mean zero, constant variance error term that varies with the state and the time period. State-level human capital investment variables such as spending on secondary education and the concentration of colleges within state are included in the $H_{j, t}$ variable. We measure the level of labor resources devoted to new ideas production as the number of high-tech workers in the state according to SIC-based categorization of high-tech employment developed by the Bureau of Labor Statistics (BLS).

The stock of innovative capacity, $A_{j, t}$, allows for a key source of endogenous technological growth in the model. As the stock of innovative capacity, or knowledge, grows the knowledge base available to inventors becomes larger. Each added idea can fuel several new ideas, and innovative capacity can, in theory, expand in an unbounded fashion. Nevertheless, expansion is not guaranteed. A large stock of knowledge may eventually mean that the major advancements have been discovered and commercialized, so that when innovative capacity is high, growth 
comes to a near standstill. Therefore, innovative capacity may be associated with rapid expansion or sluggish growth.

A host of past studies have used patents as a reflection of growth in innovative capacity (Stern, Porter, and Furman 2000; Kortum 1997; Eaton and Kortum 1996; Jaffe 1989). Patents are a good measure of technological innovation for several reasons. ${ }^{1}$ First, patents issued for genuinely novel ideas provide a good indicator of the rate at which a state is producing new technological concepts. Second, the patenting process is costly. It is unlikely, therefore, that inventors or firms will bear the cost without some reasonable probability of an economic return on their investment. Third, a patent offers the patentee exclusive rights to revenues from the material or process patented. As such, they reasonably reflect the potential economic returns to the state from technological innovations. However, it is likely that some patentees will lease patent rights to producers outside their home state or choose to commercialize the patent outside their home state. In these cases, a disjoint between patenting activity and economic development will occur. Nevertheless, patents have been widely used in the research exploring technological innovation, primarily because of the dearth of available alternatives. Therefore, while wary of the potential pitfalls of using state-level patenting as an indicator of the rate of technological innovation, we rely on this measure as the best available indicator.

According to equation (1), the level of high-tech employment affects the rate of growth in innovative capacity. And, as noted earlier, the converse is also true. That is, as growth in innovative capacity accelerates, the labor demand for high-tech labor should rise as additional workers are needed to accommodate the expanding high-tech industry. The following estimating equation characterizes this relationship:

$$
\ln H_{j, t}=\alpha+\varphi_{1} \ln Z_{j, t}+\varphi_{2} \ln W_{j, t}+\tau \ln \dot{A}_{j, t}+\eta_{j, t}+u_{j}
$$

where $W_{j, t}$ is the average wage of high-tech workers in state $j$ at time $t, Z_{j, t}$ is a vector of factors affecting the demand for labor; $u_{j}$ is a state-specific random disturbance; and $\eta_{j, t}$ is a normally distributed, mean zero, constant variance error term. Since equation (4) is a labor demand curve, we expect $\varphi_{2}<0$ to reflect the negative relationship between wages and labor demanded. The sign of $\tau$, the coefficient of innovative capacity growth, has important economic significance. When $\tau>0$, prior research increases the marginal productivity of $R \& D$, what Stern, Porter, and Furman (2000) call the "standing on shoulders" effect. A value of $\tau<0$ suggests that the stock of ideas becomes so large as to overwhelm R\&D and the marginal productivity of R\&D begins to actually fall.

\section{ESTIMATION}

As a first step, we test for endogeneity between high-tech employment and innovations in terms of the number of new patents issued, using the DWH test. ${ }^{2}$ We find that high-tech

\footnotetext{
${ }^{1}$ See Stern, Porter, and Furman (2000) for a discussion of the usefulness of patents in representing innovative capacity.

${ }^{2}$ We create an instrument for the log of high-tech employment using the exogenous variables from Table 1 . We include the residuals from that regression in a regression of patents on high-tech employment, university R\&D, industry R\&D, and state-level education variables. The coefficient of the residual from the first regression is
} 
employment and patents are indeed endogenous; thus the empirical model needs to explicitly account for endogeneity between high-tech employment and innovative capacity. The endogeneity issue may be addressed by using an instrumental variables estimator such as the one proposed by Balestra and Varadharajan-Krishnakumar (1987). ${ }^{3}$ Using this approach, we estimate the equations jointly with a generalized least squares random-effects model. The model is a two-stage generalization of the well-known random-effects model typically used to estimate systems of equations with endogenous variables. The random-effects model is used because some of the data in the model, for example school expenditures, were interpolated for missing years. Thus, the panel does not strictly contain the population values of the model variables. We examine the technological innovations over the period from 1989 through 1998 using annual data from the 50 U.S. states and the District of Columbia. The model data are transformed into natural $\operatorname{logs}$ so that the estimated coefficients are interpreted as elasticities. ${ }^{4}$ Data on employment and wages in the high-tech sector are obtained from the BLS. High tech is defined according to the Department of Commerce's classification of users and producers of IT equipment, that is, employment in high-tech industries rather than in high-tech occupations. The dollar value of R\&D expenditures performed by industry and universities as well as the number of colleges in each state was obtained from the National Science Foundation (NSF). The statelevel time series panel of patents issued is available through the U.S. Patent Office.

The estimated parameters for equation (3) are given in Table 2. The independent variables include the log of high-tech employment, the log of the number of degrees issued in the state, the $\log$ of university and industry R\&D spending, and the level of nonfarm employment in the state. Nonfarm employment is included to account for variation in the size of the labor pool among the states. About 90 percent of the variation in patenting is explained by the model. The model has a more superior fit for the time dimension than the between states' dimension. Approximately 41 percent of the interstate variation is explained by the model in contrast to 91 percent of the variation between states over time. All of the coefficients have the hypothesized sign, save the coefficient of university $R \& D$, which is negative but not significantly different from zero at the $\alpha=0.10$ level.

The model results indicate that industry $R \& D$ expenditures affect growth in innovative capacity as measured by patent activity. Interestingly, patents exhibit an inelastic response to $R \& D$ spending with an elasticity of 0.15 , statistically different from one. University R\&D is not shown to impact the growth in innovation. A host of models, including those that allowed for endogeneity of university and industry R\&D, gave similar results.

It is insightful to compare our results to the international model of growth in new-to-theworld technologies developed by Stern, Porter, and Furman (2000). Their results estimated the elasticity of industry R\&D and university R\&D to be comparable; a 1 percent increase in R\&D expenditures from either source results in a 0.009 percent increase in patenting activity. According to the model in Table 2, the elasticity of U.S. industrial R\&D expenditures is several magnitudes higher. The productivity difference between the international model of Stern, Porter,

significantly different from zero at less than $\alpha=0.0001$. Thus, we reject the null hypothesis that OLS is consistent and turn to GLS estimation of the model.

${ }^{3}$ See Baltagi (1995) for a discussion of panel data models with endogenous covariates.

${ }^{4}$ One is added to zero values when applicable. 


\section{TABLE 1}

Model Variables, Definitions and Sources (All variables are in natural $\operatorname{logs}$ )

\begin{tabular}{|c|c|c|}
\hline Variable & Definition & Source \\
\hline patents & number of patents issued by U.S. Patent Office & U.S. Patent Office \\
\hline patent stock & $\sum_{t=1987}^{1998}$ patents $_{j, t}$ for state $j$ & U.S. Patent Office \\
\hline en & nonfarm employment in th & f Labor Statistics \\
\hline echj & $\begin{array}{l}\text { ch (according to } \\
\text { classification) }\end{array}$ & Bur \\
\hline university R\&D & dollars of $R \& D$ performed by universities & National Science Foundation \\
\hline industry R\&D & R\&D performed by industry & National Science Foundation \\
\hline pop & State $\mathrm{p}$ & U.S. Census \\
\hline chy & ly wage of high-tech workers & Bureau of La \\
\hline egre & $\begin{array}{l}\text { number of university degrees issued in the } \\
\text { state }\end{array}$ & National Science Foundation \\
\hline
\end{tabular}

All variables are in natural logs. Data is from 1987 through 1998. Missing data is interpolated when necessary by averaging over preceding and posterior years.

and Furman (2000) and our model for the U.S. states probably results from the highly competitive environment faced by U.S. firms. To test this hypothesis, the international model includes a variable representing the level of competitiveness faced by firms in each country. The coefficient is negative and significant in some models, but not statistically different from zero in others. Thus, the results provide somewhat weak evidence that patenting activity between countries is sensitive to the local business environment.

The more competitive the environment, the more technological innovation will flourish. The U.S. judicial system supports strong enforcement of patent law, encouraging investment in R\&D. Additionally, all states are subject to federal anti-trust laws. Therefore, inventors and businesses are subject to essentially the same competitive environment independent of their home state. As a result, we would not expect a variable measuring state-level competitiveness to affect local patenting activity. Nevertheless, the disparity between the international and U.S. models supports the hypothesis that the competitive business environment and patent protection in the U.S. give rise to the high marginal product associated with R\&D expenditures.

Endogenous technology growth models focus on the relationship between development of new technologies and the existing stock of knowledge available to potential inventors. We characterize this relationship in our model by examining the relationship between growth in patent activity and the stock of patents. We find that the stock of knowledge is one of the key variables determining new innovative capacity. According to the model, a 1 percent increase in the stock of patents in a state corresponds to a 0.15 percent increase in new patents. This "standing on shoulders effect" bolsters evidence for the basic tenants of endogenous growth theory. Namely, the growth in ideas and new technologies is sensitive to the existing stock of knowledge, creating expansionary economic conditions. It is important to note that the coefficient estimated in our U.S. model is about half that estimated for the world model. This 
may reflect the different units of measurement or may be simply model error, but a more interesting interpretation may be at work. The U.S. is a world leader in many types of technology; thus its existing stock of knowledge at any point in time is higher than that of most countries. As a result, the lower elasticity of patents to existing knowledge may be attributable to the declining marginal product of the stock of ideas. Nevertheless, we are hesitant to rely on direct comparison of models created using different data and estimation techniques. Thus we leave further investigation of this hypothesis to future research. ${ }^{5}$

In this study, we are particularly interested in the impact of high-tech employment growth on innovative capacity. The model results support the hypothesis that the availability of a pool of high-tech labor plays a significant role in supporting technological innovation. A 1 percent increase in the number of high-tech workers in a state means innovative capacity increases by 0.43 percent. Though the response is inelastic, the labor pool turns out to be the most influential variable determining growth in innovation. This result underscores the importance of an available pool of high-tech labor to support growing innovative capacity.

The model reveals a significant relationship between human capital investment in terms of the number of university degrees issued in the state and growth in innovation. According to the model, a 1 percent increase in college degrees is responsible for a 0.26 percent increase in innovative capacity. Stern, Porter, and Furman (2000) also found that human capital investment influenced patent growth internationally. It is not surprising that this is also true regionally.

\section{TABLE 2}

Two-Stage Generalized Least Squares Random Effects Model of Innovative Capacity: Dependent Variable is the Natural Log of Average Patents in the State. Coefficients are Elasticities

\begin{tabular}{lcccc}
\hline Variable & Coef. & Std. Err & $\mathrm{z}$ & $\mathrm{P}>|\mathrm{z}|$ \\
\hline techjobs & 0.4251 & 0.1511 & 2.81 & 0.005 \\
degrees & 0.2587 & 0.1216 & 2.13 & 0.033 \\
patent stock & 0.1522 & 0.0214 & 7.12 & 0.000 \\
university R\&D & -0.1080 & 0.0775 & -1.39 & 0.164 \\
industry R\&D & 0.1582 & 0.0256 & 6.17 & 0.000 \\
nfemp & 0.0393 & 0.0223 & 1.76 & 0.078 \\
$\mathrm{C}$ & 0.1137 & 1.7227 & 0.07 & 0.947 \\
\hline$\sigma\left(v_{t, j}\right)$ & 0.121 & & $R^{2}$ within & 0.409 \\
$\sigma\left(\varepsilon_{j}\right)$ & 0.216 & & $R^{2}$ between & 0.914 \\
$\rho$ & 0.239 & & $R^{2}$ overall & 0.895 \\
\hline
\end{tabular}

Instrumented: techjobs

Instruments: degrees, patent stock, university R\&D, industry R\&D, nfemp, colleges, wages, pop

\footnotetext{
${ }^{5}$ Stern, Porter, and Furman (2000) estimate an OLS model using a panel of 17 OECD countries over 20 years. The international nature of the data set makes it necessary to control for variation in the level of intellectual property protection, openness to trade, and the stringency of anti-trust laws in each country. Therefore, the resulting model, though based on similar economic concepts, is estimated using a different econometric technique and a different regressor set than the one reported in this paper.
} 


\section{TABLE 3}

Two-Stage Generalized Least Squares Random Effects Model of High-Tech Employment Demand: Dependent Variable is Natural Log of the Number of High-Tech Jobs. Coefficients are Elasticities

\begin{tabular}{lrlcl}
\hline Variable & Coef. & Std. Err & $\mathrm{z}$ & $\mathrm{P}>|\mathrm{z}|$ \\
\hline patents & 1.3363 & 0.2387 & 5.60 & 0.00 \\
patent stock & -0.0793 & 0.0726 & -1.09 & 0.275 \\
industry R\&D & -0.0489 & 0.0478 & -1.02 & 0.306 \\
nfemp & -0.0527 & 0.1003 & -0.53 & 0.600 \\
techwages & -0.1270 & 0.3642 & -0.35 & 0.727 \\
$\mathrm{C}$ & -3.2704 & 2.2146 & -1.48 & 0.140 \\
\hline$\sigma\left(\eta_{t, j}\right)$ & 0.869 & & $R^{2}$ within & 0.058 \\
$\sigma\left(u_{j}\right)$ & 0.435 & & $R^{2}$ between & 0.767 \\
$\rho$ & 0.800 & & $R^{2}$ overall & 0.725 \\
\hline \multicolumn{4}{l}{ Instrumented: patents } \\
Instruments: degrees, patent stock, university R\&D, industry R\&D, nfemp, \\
colleges, wages, pop
\end{tabular}

Two simple models of demand for high-tech labor are reported in Tables 3 and 4. The model is estimated using the same two-stage GLS approach used to model growth in innovative capacity. The dependent variable, techjobs, is the natural log of the number of jobs (in thousands) in the high-tech sector. In Table 3, the independent variables include the log of new patents, the log of the stock of patents, the log of the number of college degrees issued, and the $\log$ of university and industry R\&D expenditures. The log of nonfarm employment is included to account for state-by-state variation in the size of the labor pool. To account for endogeneity, we estimate an instrument for patents. The instrumental variables are the same as for the patent equation, namely degrees, university and industry $\mathrm{R} \& \mathrm{D}$, high-tech wages, the patent stock, and population. All instruments are in logs.

In Table 3, only the coefficient of patents is significantly different from zero. The within groups $R^{2}$ is a meager 0.058 . However, the overall $R^{2}$ is 0.73 . The relatively high overall $R^{2}$ value together with the low t-statistics suggests there may be problems with multicollinearity in the regression. We perform a set of partial correlations among the independent variables. We find high partial $R^{2}$ values $(>0.35)$ for groups of three for industry R\&D, nfemp, techwages, and patent stock, suggesting that some multicollinearity is present. Theoretical underpinning exist for a positive and significant relationship between increased industry $R \& D$ spending and labor demand, so we choose to retain it in the next regression in Table IV. Likewise, wages should be a critical factor in determining high-tech employment. Thus, we choose to keep that variable. We drop nonfarm employment and the patent stock in an effort to minimize problems with multicollinearity.

The results of the resulting regression are reported in Table 4. The model explains 73 percent of the variation in high-tech employment. Interstate variation dominates the data; 7.7 percent of the variation within states is explained compared to 77.7 percent between the states over time. Consistent with labor demand theory, the average weekly wage of high-tech workers 
is negatively related to the quantity of high-tech labor demanded. An inelastic response is observed with a 1 percent decrease in the wage rate increasing labor demanded by 0.42 percent. The regression results also show that new patent activity acts as a stimulus for high-tech employment growth. A 1 percent increase in patents is associated with a 1.12 percent increase in high-tech employment. Finally, even the new specification does not find a correlation between industry R\&D and high-tech employment growth. ${ }^{6}$

\section{TABLE 4}

Two-Stage Generalized Least Squares Random Effects Model of High-Tech

Employment Demand: Dependent Variable is Natural Log of the

Number of High-Tech Jobs. Coefficients are Elasticities

\begin{tabular}{lrccc}
\hline Variable & Coef. & Std. Err & $\mathrm{z}$ & $\mathrm{P}>|\mathrm{z}|$ \\
\hline patents & 1.121 & 0.099 & 11.36 & 0.000 \\
industry R\&D & -0.026 & 0.039 & -0.64 & 0.514 \\
techwages & -0.420 & 0.203 & -2.08 & 0.038 \\
$\mathrm{C}$ & -1.636 & 1.073 & -1.53 & 0.127 \\
\hline$\sigma\left(\eta_{t, j}\right)$ & 0.726 & & $R^{2}$ within & 0.077 \\
$\sigma\left(u_{j}\right)$ & 0.409 & & $R^{2}$ between & 0.777 \\
$\rho$ & 0.760 & & $R^{2}$ overall & 0.736 \\
\hline
\end{tabular}

Instrumented: patents

Instruments: degrees, patent stock, university R\&D, industry R\&D , nfemp, colleges, wages, pop

According to the model, patenting has a strong and positive impact on state-level high-tech employment growth. A 1 percent increase in patenting activity corresponds to a 4.6 percent increase in high-tech employment. Clearly growth in innovative capacity translates directly into economic growth within a state. This is not surprising, as California and other high-tech centers enjoyed income growth throughout the 1990s, much of which can be attributed either directly or indirectly to growing innovative capacity. As a result, many state and local governments are considering programs to entice high-tech and venture capital firms to locate in their state. This research provides direct evidence of the benefits, in terms of employment growth, that could be captured by successful states.

\section{CONCLUSION}

We find that the stock of knowledge (standing on shoulders effect), industry R\&D expenditures, and the number of high-tech employees positively and statistically significantly explain the rate of change of innovation among the states during the 1990s. The stock of human capital, measured by the number of university degrees awarded, also influences the innovation rate. Our second equation, a simple model of high-tech employment growth, suggests that

\footnotetext{
${ }^{6}$ Several specifications of the model were estimated seeking to find a relationship between R\&D and high-tech employment growth, including total R\&D spending, university R\&D spending, and federal R\&D spending. None of the relationships were significantly different from zero.
} 
patenting activity and wages in the high-tech sector are the primary forces influencing the demand for high-tech labor. That is, we find strong evidence of endogeneity between employment growth and innovative capacity. As a result, our findings may be more robust than previous research that does not address endogeneity and model-structure issues.

Our findings have policy implications. States that are interested in developing high-tech centers should take notice. A large portion of high-tech growth is dependent upon forces largely out of their control, namely wages and the rate of innovative activity. Nevertheless, states may indirectly influence the size of their high-tech sectors through supporting growth in innovative capacity by placing emphasis on the quality and accessibility of education within the state. Further, encouraging new idea growth by supporting R\&D investment may eventually pay off in the form of the coveted growth in high-paying, high-tech jobs. Still, the significance of the time dimension suggests that high-tech, "new economy" development occurs on the shoulders of previous work. That is, there are few, if any, quick fixes for local economies lacking a high-tech employment base.

\section{REFERENCES}

Anderson, A.E., C. Anderstig, and B. Harsman, 1990. "Knowledge and Communications Infrastructure and Regional Economic Growth," Regional Science and Urban Economics 20, $359-76$.

Anselin, L., A. Varga, and Z. Acs, 1997. "Local Geographic Spillovers Between University Research and High Technology Innovations," Journal of Urban Economics 42, 422-48.

Balestra, P. and J. Varadharajan-Krishnakumar, 1987. "Full Maximum-Likelihood Estimation of a System of Simultaneous Equations with Error Components Structure," Econometric Theory $3,223-46$.

Baltagi, B.H., 1995. Econometric Analysis of Panel Data. John Wiley and Sons: New York.

Eaton, J. and S. Kortum, 1996. "Trade In Ideas: Patenting and Productivity in the OECD," Journal of International Economics 40(3-4), 251-78.

Feldman, M.P. and R. Florida, 1994. "The Geographic Sources of Innovation: Technological Infrastructure and Product Innovation in the United States," Annals of the Association of American Geographers 84(2), 210-29.

Jaffe, A.B., 1989. "Real Effects of Academic Research," American Economic Review 70, 95770.

Howells, J.R., 1984. "The Location of Research and Development: Some Observations and Evidence from Britain," Regional Studies 18, 13-29.

Kortum, S., 1997. "Research, Patenting, and Technological Change," Econometrica 65(6), 13891419. 
Malecki, E., 1981. "Federal R\&D Spending in the United States of America: Some Impacts on Metropolitan Economies," Regional Studies 26, 123-36.

Markusen A., P. Hall, and A. Glasmeier, 1986. High Tech America: The What, How, Where, and Why of Sunrise Industries. Allen and Unwin: Boston.

Mowery, D.C. and N. Rosenberg, 1993. "The U.S. National Innovative System,” in R. Nelson (ed.), National System of Innovation. Oxford University Press: New York.

Nelson, R., 1993. National Innovation Systems: A Comparative Analysis. Oxford University Press: New York.

Porter, M.E., 1990. The Competitive Advantage of Nations. Free Press: New York.

Romer, P., 1990. “Endogenous Technological Change,” Journal of Political Economy 98, S71S102.

Rowen, H.S., 2000. "Serendipity or Strategy: How Technology and Markets Came to Form Silicon Valley," in Chong-Moon Lee, William F. Miller, Marguerite Gong Hancock, and Henry S. Rowen (eds.), The Silicon Valley Edge: A Habitat for Innovation and Entrepreneurship. Stanford University Press: Stanford, CA.

Sivitanidou, R. and P. Sivitanides, 1995. "The Intrametropolitan Distribution of R\&D Activities; Theory and Empirical Evidence," Journal of Regional Science 35, 391-415.

Stern, S., M.E. Porter, and J.L. Furman, 2000. "The Determinants of National Innovative Capacity," National Bureau of Economic Research Working Paper 7876: Cambridge, MA.

Stohr, W., 1986. "Regional Innovation Complexes," Papers of the Regional Science Association $59,29-34$.

Wilkerson, C., 2002. "How High-Tech is the $10^{\text {th }}$ District?" Federal Reserve Bank of Kansas City, Economic Review 87(2), 27- 53. 